\title{
Using volunteers to improve the experience of older patients in the emergency department
}

\author{
Brittany Ellis, MBChB, MSc ${ }^{* \neq}$; Don Melady, MD, MSc(Ed)ฐ; Nicoda Foster, MPHף; Samir Sinha, MD, \\ DPhil§ף; Vicki Lau, BA, CTRSף; Stephanie Saraga, RN ${ }^{\ddagger \# ; ~ S h e l l e y ~ L . ~ M c L e o d, ~ M S c, ~ P h D \S ~}$
}

\begin{abstract}
CLINICIAN'S CAPSULE
What is known about the topic?

Recently, specialized volunteer programs have been developed and implemented in the emergency department (ED), allowing volunteers to perform activities previously not considered possible.

What did this study ask?

We describe the development and implementation of the Maximizing Aging Using Volunteer Engagement in the Emergency Department (MAUVE +ED) program and report the activities of the MAUVE + ED volunteers during the first 6 months.

What did this study find?

The MAUVE + ED program can train skilled volunteers to provide additional care to older adults and their families/ carers in the ED.

Why does this study matter to clinicians?

The development and implementation of the MAUVE + ED program represents an innovative and advanced role for the use of skilled volunteers in the ED setting.
\end{abstract}

\section{ABSTRACT}

Objectives: The Maximizing Aging Using Volunteer Engagement in the Emergency Department (MAUVE + ED) program connects specially trained volunteers with older patients whose personal and social needs are not always met within the busy ED environment. The objective of this study was to describe the development and implementation of the MAUVE + ED program.

Methods: Volunteers were trained to identify and approach older patients at risk for adverse outcomes, including poor patient experience, and invite such patients to participate in the program. The program is available to all patients $>65$ years, and those with confusion, patients who were alone, those with mobility issues, and patients with increased length of stay in the ED. Volunteers documented their activities after each patient encounter using a standardized paper-based data collection form.

Results: Over the program's initial 6-month period, the MAUVE + ED volunteers reported a total of 896 encounters with 718 unique patients. The median time (interquartile range [IQR]) a MAUVE volunteer spent with a patient was 10 minutes $(I Q R=5,20)$, with a range of 1 to 130 minutes. The median number of patients seen per shift was $7(\operatorname{IQR}=6,9)$, with a range of 1 to 16 patients per shift. The most common activities the volunteer assisted with were therapeutic activities/social visits ( $n=859 ; 95.9 \%)$, orientation activities ( $n=501 ; 55.9 \%)$, and hydration assistance $(n=231 ; 25.8 \%)$. The least common were mobility assistance $(n=36 ; 4.0 \%)$, and vision/hearing assistance $(n=13 ; 1.5 \%)$.

Conclusions: Preliminary data suggest the MAUVE + ED volunteers were able to provide additional care to older adults and their families/carers in the ED.

\section{RÉSUMÉ}

Contexte: Le programme MAUVE + ED (Maximizing Aging Using Volunteer Engagement in the ED) permet de mettre en relation des bénévoles spécialement formés et des personnes âgées dont les besoins personnels et sociaux ne sont pas toujours satisfaits dans l'environnement trépidant des services des urgences (SU). L'étude visait à décrire l'élaboration et la mise en œuvre du programme MAUVE + ED.

Méthode: Des bénévoles ont reçu une formation particulière afin d'être en mesure de reconnaître et d'aborder des personnes âgées susceptibles de connaître des résultats défavorables, dont une mauvaise expérience à I'hôpital, et de les inviter à participer au programme. Étaient admissibles toutes les personnes $>65$ ans ainsi que celles qui étaient en état de confusion, qui vivaient seules, qui éprouvaient des problèmes de mobilité ou dont la durée de séjour au SU se prolongeait. Les bénévoles inscrivaient sur un formulaire papier, uniforme,

From the *Saskatchewan Health Authority, Saskatoon, SK; ${ }^{\dagger}$ Department of Emergency Medicine, College of Medicine, University of Saskatchewan,

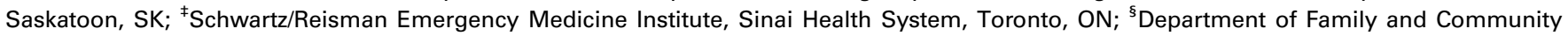
Medicine, Division of Emergency Medicine, University of Toronto, Toronto, ON; ${ }^{9}$ Department of Medicine, Division of Geriatric Medicine, University of Toronto, Toronto, ON; and the "Lawrence S. Bloomberg Faculty of Nursing, University of Toronto, Toronto, ON.

Correspondence to: Dr. Brittany Ellis, Box 16, 103 Hospital Drive, Saskatoon, SK, Canada; Email: b.ellis@usask.ca

(c) Canadian Association of Emergency Physicians 2020

CJEM 2020;22(4):514-518

DOI 10.1017/cem.2020.9 
de collecte de données les activités réalisées après chacune des rencontres avec les patients.

Résultats: Les bénévoles participant au programme MAUVE + ED ont enregistré, au cours de la période de initiale de 6 mois, 896 rencontres avec 718 patients différents. La durée médiane (écart interquartile [EIO]) des rencontres était de 10 minutes (5-20) par patient et la plage de valeurs variait de 1 à 130 minutes. Le nombre médian (EIQ) de patients rencontrés par poste de travail était de 7 (6-9) et la plage de valeurs variait de 1 à 16 patients. Les tâches les plus fréquentes effectuées par les bénévoles comprenaient des activités thérapeutiques ou des visites sociales $(n=859 ; 95,9 \%)$, des activités d'orientation
( $n=501 ; 55,9 \%)$ et l'aide à I'hydratation ( $n=231 ; 25,8 \%)$; les moins fréquentes comprenaient l'aide à la mobilité ( $n=36 ; 4,0 \%$ ) et la fourniture d'aides à la vision ou à l'audition ( $n=13 ; 1,5 \%)$.

Conclusion: $D^{\prime}$ après les données préliminaires, les bénévoles participant au programme MAUVE + ED auraient fourni effectivement des soins additionnels aux personnes âgées et à leurs familles ou à leurs aidants, au SU.

Keywords: Emergency department, older patients, patient experience, volunteers

\section{INTRODUCTION}

Volunteers have had a long-standing presence in health care, with roles dating as far back as the 17th century when organized volunteer initiatives were established to provide care and support for the "elderly, incapacitated, and sick." ${ }^{1}$ Emergency departments (EDs) have increasingly welcomed the contributions of volunteers to provide a wide range of services. Patient-focused, nonclinical volunteer services offer many benefits, including reduced social isolation, increased emotional support, assistance with nutrition and hydration needs, and patient navigation and mobility assistance within the ED. ${ }^{2,3}$ These volunteer activities liberate time for health care providers to focus on their clinical duties, reducing overall care costs and improving efficiency. A previous study by Handy and Srinivasan found that volunteers in 31 hospitals in Toronto, Canada, provided the equivalent of \$6.84 in services for every dollar invested in the volunteer program, representing a $684 \%$ return on investment. ${ }^{4}$

Over the past 2 decades, a series of specialized volunteer programs have been developed and implemented, allowing volunteers to perform activities previously not considered possible. ${ }^{5,6}$ The best-known example is the Hospital Elder Life Programme (HELP), which has been implemented in multiple settings, principally Acute Care for Elders (ACE) units, to support admitted older patients, to decrease delirium, and improve functional outcomes at discharge. ${ }^{5}$ In HELP, older patients ( $\geq 70$ years) are screened on admission for six risk factors (cognitive impairment, sleep deprivation, immobility, dehydration, and vision or hearing impairment) and targeted interventions are implemented in an inpatient setting by an interdisciplinary team, often including trained volunteers, to specifically prevent delirium and minimize functional decline. The Care and Respect for Elders with Emergencies (CARE) program is a geriatricfocused volunteer program designed to help prevent complications such as falls, delirium and the use of restraints, and functional decline in vulnerable elders in the ED. ${ }^{6}$ The CARE program consists of bedside volunteer interventions ranging from conversation to various short activities designed to engage and reorient high-risk, older, unaccompanied individuals in the ED.

At our institution, we have designed a volunteer program to improve the patient experience of older adults and reduce their risk of decline while in the ED. The Maximizing Aging Using Volunteer Engagement in the ED (MAUVE + ED) program connects specially trained volunteers with older adults whose personal and social needs are not always well met within the traditional chaotic ED environment. The objective of this study was to describe the development and implementation of the MAUVE + ED program and report the activities and experiences of the MAUVE + ED volunteers during the first 6 months of the program.

\section{METHODS}

\section{Study design, setting, and participants}

The MAUVE + ED program was implemented in the ED (annual census 65,000) of a large academic tertiary care hospital: Mount Sinai Hospital in Toronto, ON. The program was designed in conjunction with an established inpatient volunteer program under the same name 
(MAUVE). The program was developed by an interprofessional team, including representation from the disciplines of geriatric medicine, emergency medicine, volunteer services, recreational therapy, speech and language pathology, occupational therapy, and physiotherapy. The MAUVE + ED program uses a team of specially trained volunteers to promote patient, caregiver, and staff well-being. The volunteers are selected following an application and interview process. Key attributes of successful applicants included highly selfmotivated, personable, emotionally mature, diversified experiences/careers, and a willingness to commit to at least one 4-hour volunteer shift per week for a minimum of 6 months.

Before the implementation of the MAUVE + ED program, all selected volunteers completed a mandatory 8-hour in-person training session consisting of didactic teaching, training on common concerns faced by older people in the ED, and training around patient privacy and confidentiality. Didactic teaching topics covered included delirium and how to mitigate its risk factors, hydration and nutrition, swallowing, falls and mobility, and dementia. This was followed by at least two shifts in the ED where the volunteer was buddied with a previously trained, experienced MAUVE + ED volunteer to help orient the new volunteer to the ED and its staff. For the initial set of volunteers, where no buddying was possible, individuals involved in the training and development of the MAUVE + ED program were readily available in the hospital during their first shifts.

Volunteers were trained to recognize patient characteristics that may cause an individual to be at greater risk for adverse outcomes in the ED and, when possible, specifically approach such patients to participate in the MAUVE + ED program. Potential patient characteristics included age $>75$ years, appearing confused, being alone, having mobility issues, and patients with an increased length of stay in the ED. Additionally, ED staff were encouraged to contact the MAUVE+ED volunteers directly to visit patients they believed could benefit from the program.

Volunteers were encouraged to complete social visits, speak to patients to identify their nonclinical needs, and assist patients with their nutrition/hydration needs, re-orientation to day/time/place, and ambulation within the ED. MAUVE + ED volunteers were also encouraged to provide emotional support and caregiver respite. Volunteers were provided with a cart containing single- use items for patient use. This included hearing amplifiers, reading glasses, sleep masks, ear plugs, stress balls, newspapers, puzzles, novels and large print books, and personal care items including combs and toothbrushes.

MAUVE + ED volunteers documented their activities after each patient encounter using a standardized paperbased data collection form designed specifically for this study. All volunteer services were only initiated following explicit patient permission. The volunteers were supported in the ED by the clinical nurse educator, as well as a recreational therapist who also co-led their training. If a volunteer had concerns regarding the health of a patient, or obtained potentially new information, they reported this directly to the patient's primary nurse. The descriptive study protocol was approved by the hospital's research ethics board.

\section{Patient and public involvement}

The MAUVE + ED program was directly informed by input from our volunteers.

\section{Data analysis}

The activity data collected by the volunteers were entered directly into a study-specific Microsoft Excel database (Microsoft Corporation, Redmond, WA, USA) by trained research assistants. Microsoft Excel was used to summarize means with standard deviations (SDs), medians with interquartile ranges (IQRs), or frequencies where appropriate.

\section{RESULTS}

Over the program's 6-month period, MAUVE + ED volunteers reported a total of 896 encounters with 718 unique patients. The mean age of the participating patients was 81 years $(\mathrm{SD}=11)$ and $439(61.1 \%)$ were female. Each patient had a mean of 1.6 visits $(\mathrm{SD}=0.7)$ from a MAUVE + ED volunteer per ED visit, with a range of 1 to 4 visits. The median time a MAUVE + ED volunteer spent with a patient was 10 minutes $(\mathrm{IQR}=5,20)$, with a range of 1 to 130 minutes. The median number of patients seen per shift was 7 (IQR $=$ $6,9)$, with a range of 1 to 16 patients per shift.

Table 1 reports the activities performed by the MAUVE + ED volunteers. The most common volunteer 


\begin{tabular}{|c|c|c|}
\hline Activity & Examples of primary activities & $\begin{array}{l}\text { Number of } \\
\text { patient encounters } \\
(\mathrm{N}=896)\end{array}$ \\
\hline Orientation & $\begin{array}{l}\text { Paper left with patient to remind of date, time, location; verbal discussion with } \\
\text { patient regarding date, time, location }\end{array}$ & $859(95.9 \%)$ \\
\hline Therapeutic activities & $\begin{array}{l}\text { Social visits; supply of activities, including puzzles (sudoku, cross-word, word } \\
\text { search), books (including large print), magazines, newspapers, stress balls }\end{array}$ & $501(55.9 \%)$ \\
\hline Mobility assistance & $\begin{array}{l}\text { Assist patients to the washroom; assist patients walking around the emergency } \\
\text { department to stay mobile; assist with repositioning, assist transfer to/from bed } \\
\text { or chair }\end{array}$ & $36(4.0 \%)$ \\
\hline Eating & Providing food, removing food packages, assist with cutting food & $231(25.8 \%)$ \\
\hline Hydration & Providing drinks (water, juice, tea, coffee), removing packaging & $132(14.7 \%)$ \\
\hline Vision/hearing & Provision of assistive hearing devices, magnifying lenses, reading glasses, ear plugs & $13(1.5 \%)$ \\
\hline
\end{tabular}

activities conducted were therapeutic activities/social visits $(\mathrm{n}=859 ; 95.9 \%)$, the least common was vision/ hearing assistance $(n=13 ; 1.5 \%)$. In addition to the prescribed core activities, volunteers were able to provide additional support to patients and their families. For example, one volunteer documented a 90-year-old woman "was very agitated but I managed to calm her down - she just needed a chat." Volunteers were trained to recognize older people at risk of adverse outcomes in the ED and effectively did so. One volunteer documented "The patient has dementia. Very agitated. In triage area for hours - sat with her." Volunteers also engaged in meaningful activities that other care providers may not have capacity to do. One volunteer documented, "spent 1 hour with patient. He was a wanderer waiting to be taken home." Another volunteer spent over 130 minutes with a 72-year-old patient who was anxious and alone. Additional entries made by the volunteers reflected the natural vulnerability of visiting the ED. One volunteer documented, "no family/friends visiting, doesn't have teeth/dentures, provided soft foods banana Jell-O (nurse approved)."

\section{DISCUSSION}

The development and implementation of the MAUVE + ED program represents an innovative and advanced role for the use of skilled volunteers in the ED setting. Our study demonstrated that MAUVE + ED volunteers were able to assist over $700 \mathrm{ED}$ patients within a 6-month period. While we were only able to share a small number of qualitative volunteer entries in this manuscript, it was evident that volunteers, patients, and those who attended the ED with them had positive experiences with the MAUVE +ED program. We anticipate the program helps to enhance the patient experience and possibly prevents potential decline; however, further evaluation is required.

As previously highlighted, similar programs have been described. One of the first programs to use volunteers with advanced training to work with older patients was the Hospital Elder Life Program (HELP), designed to prevent functional and cognitive decline of older persons during hospitalization. ${ }^{5}$ The Care and Respect for Elders with Emergencies (CARE) program is a geriatricfocused volunteer program designed to help prevent complications such as falls, delirium and the use of restraints, and functional decline in vulnerable elders in the ED. ${ }^{6}$ While outcome data are not available for the CARE program, the HELP program has demonstrated reductions in both total number of episodes of delirium, as well as number of days with delirium through standardized care protocols focused on six risk factors for delirium: cognitive impairment, sleep deprivation, immobility, visual impairment, hearing impairment, and dehydration. ${ }^{7}$ Our MAUVE + ED program was developed using similar principles, and volunteers were able to assist in many of these key areas.

In addition to developing similar volunteer programs targeted toward older people, it is likely that other vulnerable ED users, such as those with mental health and addictions concerns and homeless patients, would benefit from similar approaches. 


\section{LIMITATIONS}

This study was conducted in an academic single-center tertiary care ED, with a well-supported geriatric emergency medicine program that sees all staff trained in geriatric care principles using the online training modules at www.Geri-EM.com. These results might not be generalizable to other settings but does confirm that many older patients visiting a busy ED can be supported in specific ways by specially trained volunteers. Implementation of the MAUVE + ED program required coordination from many disciplines in the hospital, namely geriatric medicine, emergency medicine, and volunteer services. While there were no direct costs to the ED in using volunteers, there were indirect financial expenses associated with the recruitment, training, and management of the MAUVE + ED volunteers and the support of the hospital's program coordinator.

\section{CONCLUSIONS}

Our results suggest the MAUVE + ED program can successfully train skilled volunteers to provide additional care to older adults and their families/carers in the ED. Future studies are needed to evaluate cost-effectiveness, patient and staff satisfaction and long-term outcomes of the program.
Competing interests: None of the authors have conflicts of interest to disclose.

Financial support: This research received no specific grant from any funding agency, commercial or not-for-profit sectors.

\section{REFERENCES}

1. Lautenschlager J. Volunteering: a traditional Canadian value. Voluntary Action Program, Department of Canadian Heritage; (1992). Available at: http://en.copian.ca/library/research/ heritage/compartne/pdfdocs/tradval.pdf (accessed October 19, 2019).

2. Garrison M, Wolf J. The Role of the Volunteer in Improving Patient Experience. Bedford, TX: The Beryl Institute: White Papers; 2016. Available at: https://www.theberylinstitute. org/store/ViewProduct.aspx?id=6373089 (accessed February 3, 2020).

3. Schultz C, Stratton SJ. Improving hospital surge capacity: a new concept for emergency credentialing of volunteers. Ann Emerg Med 2007;49(5):602-9.

4. Handy F, Srinivasan N. Valuing volunteers: an economic evaluation of the net benefit of hospital volunteers. Nonprofit Volunt Sect Q 2014;33(1):28-54.

5. Inouye SK, Bogardus Jr ST, Baker DI, Leo-Summers L, Cooney Jr. LM The Hospital Elder Life Program: a model of care to prevent cognitive and functional decline in older hospitalized patients. $\mathcal{F}$ Am Geriatr Soc 2000;48(12):1697-706.

6. Sanon M, Baumlin KM, Kaplan SS, Grudzen CR. Care and respect for elders in emergencies program: a preliminary report of a volunteer approach to enhance care in the emergency department. 7 Am Geriatr Soc 2014;62(2):365-70.

7. Inouye SK, Bogardus ST, Charpentier PA, et al. A multicomponent intervention to prevent delirium in hospitalized older patients. N Engl 7 Med 1999;340:669-76. 